\title{
Horror in mainstream- en cult cinema: is het genre extremer geworden?
}

\author{
Veerle Pashley ${ }^{1}$
}

\author{
"Horror shows us that the control we believe we have \\ is purely illusory. \\ Every moment we teeter in chaos and oblivion" \\ -Uitspraak van horrorschrijver Clive Barker (www.clivebarker.info)-
}

\begin{abstract}
Ever since the creation of silent movies, directors aim to shock the audience with explicit scenes of violence. Yet, little attention has been given to the evolution of horror movies. In order to create 'monsters', 'dark locations' and 'explicit scenes of violence' directors have to experiment with storylines and new techniques, if they want to shock the audience. The aim of this paper is to examine whether or not horror has become more violent (more extreme) throughout film history. Hence, we will discuss the historic evolution of horror movies in mainstream cinema (films that reached a large audience) and cult cinema (films which have a select, mostly fan based, audience).
\end{abstract}

\section{Keywords: horror, violence, visual data}

\section{Inleiding: extreem gewelddadige films}

Extreem geweld in kunst is van alle tijden en zit verweven in heel wat aspecten van onze dagelijkse cultuur. We worden voortdurend geconfronteerd met wat we als samenleving definiëren als zijnde 'goed' en 'kwaad'. Het zit verweven in de muziek waar we naar luisteren, de schilderijen die we bezichtigen, de musea die we bezoeken, de kranten en boeken die we lezen, de opvoeding die we meekrijgen, de levensbeschouwing die we navolgen en ga zo maar door. Iedereen groeit op en leeft met een idee over wat geweld en/of gruwel is en hoe we daar mee omgaan.

Het feit dat extreem geweld of horror ${ }^{2}$ verweven zit in onze dagdagelijkse cultuur zou doen vermoeden dat er heel wat bronnen ter beschikking zijn. Helaas zijn er veel taboes over de horrorfilms waardoor de beschikbare literatuur beperkt of eenzijdig is. Doorgaans worden dergelijke films besproken als onderdeel van de kunstgeschiedenis in het algemeen en de filmgeschiedenis in het bijzonder (Dethier, 1996; Thompson \& Bordwell, 2003). Het is duidelijk dat horror als filmgenre zeer beknopt wordt bestudeerd. Dixon (2010) levert een dankbare meerwaarde door een overzicht te geven van horrorfilms doorheen de geschiedenis. Hoewel deze werken de focus leggen op het historisch kader wordt weinig aandacht besteed aan het feit dat horrorfilms eveneens een belangrijke bijdrage kunnen leveren aan onze culturele samenleving. Dergelijke films geven immers een impressie over geweld en dit wordt vaak symbolisch weergegeven.

Culturele criminologie geeft ons een platform om na te denken over identiteit, symboliek en visuele representaties. Geweld maakt onderdeel uit van onze samenleving en iedere dag

\footnotetext{
${ }^{1}$ Veerle Pashley is assistent aan de Universiteit Gent. Ze bereidt een doctoraat voor in de criminologische en sociaal-militaire wetenschappen (joint degree Universiteit Gent, Vrije Universiteit Brussel en de Koninklijke Militaire School).

${ }^{2}$ In dit artikel worden beide concepten synoniem gebruikt.
} 
worden we geconfronteerd met visueel materiaal over criminaliteit én de reactie op criminaliteit. Hayward \& Presdee (2010) bespreken in hun boek "Framing Crime: Cultural Criminology and the Image" hoe beelden een representatie geven over geweld en dat het onderscheid tussen het visuele (of virtuele) en de realiteit steeds moeilijker te bepalen is.

In horrorfilms wordt het aspect "monster" frequent gebruikt als symbool voor de afbeelding van datgene wat we als samenleving percipiëren als "het kwade" (Landis, 2011). Tal van films hebben zogenaamde horroriconen voortgebracht (Jason Voorhees, Leatherface, Freddy Kruger...) die hieraan een zekere identiteit geven (Bradley, 2004). Of het nu gaat over beelden, muziek of literatuur, doorheen gans de kunstgeschiedenis trachten mensen geweld symbolisch weer te geven (Markesinis, 2007). Ook analyses van narratieve genres zoals de zogenaamde 'gothic novels' (Garrett, 2003) illustreren hoe mensen aangetrokken worden door de symboliek van geweld.

Horrorfilms geven een impressie van geweld in zijn meest extreme vorm. Ze zijn geënt op het creëren van sensatie bij de toeschouwer op een impliciete en expliciete manier. Hoe gewelddadig horrorfilms ook moge zijn, mensen zullen altijd geneigd zijn om er naar te kijken. Zo is er een studie (Palmer, 2008) die nagaat in hoeverre horrorfilms angstgevoelens opwerpen. Door geweld toe te schouwen, en de daarmee samenhangende spanning, ervaren we een zekere 'arousal'. Onze adrenaline gaat sneller en het prikkelt ons om ernaar te kijken.

Horrorfilms werken in op sensatie en zijn verweven van symboliek. Ondanks het feit dat het gevoelens van afkeer en gruwel oproept, wekt het evenzeer in op de interesse van toeschouwers. 'Horror' is Latijn voor verschrikking en wordt door de Van Dale omschreven als 'griezelfilm' (1996). Het is een breed concept waar verschillende betekenissen aan wordt gegeven. In dit artikel definiëren we een horrorfilm als een fictieve film waarin het hoofddoel van de verhaallijn geënt is op expliciete of impliciete gebeurtenissen van extreem geweld. Hoewel we, strikt objectief gezien, films als 'Jaws' niet kunnen thuisbrengen onder de noemer "horror" zijn dergelijke verhaallijnen bedoeld om het publiek te choqueren en angst aan te jagen. We hebben eveneens rekening gehouden met soortgelijke films in onze analyse.

Zoals we in dit artikel zullen zien is er sinds de jaren zestig - zeventig een toegenomen tolerantie in het Westen ten aanzien van extreem geweld in films. Eenzelfde transitie kunnen we terugvinden in het pornogenre. Beelden van martelpraktijken, moorden en verkrachtingen worden tot in het kleinste detail verfilmd. Vraag is of horror het publiek minder choqueert of dat we op een andere manier omgaan met sensatie.

In dit artikel gaan we na of horror in mainstream- en cult cinema al dan niet extremer is geworden. Vooreerst zoomen we in op de methodologie, met name de (audio)visuele gegevensverzameling. Ten tweede bespreken we de geschiedenis van de horrorfilms waarbij we een antwoord trachten te vinden op de vraag of horror al dan niet extremer is geworden. Tot slot eindigen we het artikel met een slotbeschouwing.

\section{Methodologie}

Dagdagelijks worden we geconfronteerd met (audio)visueel beeldmateriaal. Films, series, websites, kranten, tijdschriften, foto's, cartoons en videoclips geven ons een representatie van criminaliteit en de reactie op criminaliteit. Dergelijke informatie is van onschatbare waarde. Het geeft ons een indicatie hoe mensen kijken naar geweld. Beelden vertellen ons eveneens iets over de reactie van de maatschappij op criminaliteit. Ze hebben invloed op de perceptie 
van toeschouwers (Vanderveen, 2010: 390). Desondanks wordt visuele dataverzameling relatief weinig toegepast in de criminologische wetenschappen. Onze methodologie, die kwalitatief van aard is, is toegespitst op visuele dataverzameling waarin we de focus leggen op horror of het gebruik van extreem geweld in films.

Om onze horrorfilms te selecteren hebben we gebruikt gemaakt van verschillende tools. Vooreerst is de 'International Movie Database' (www.imdb.com) een dankbare zoekmachine. Deze databank groepeert wereldwijd informatie over alle films. Gebruikers kunnen een zoekterm ingeven volgens genre, titel, sleutelwoord, series, films, karakters, bedrijven enzovoorts. Dit laat ons toe om een breed spectrum van filminformatie op te zoeken. Als men zoekt op 'horror als genre' krijgt men een lijst van meer dan 17000 titels. Door geavanceerd te zoeken kan men gerichter tewerk gaan door bijvoorbeeld de periode of het jaartal in te geven. Per film krijgt men informatie over het jaar van uitgave, de verhaallijn, de regisseur, de acteurs, de filmploeg, het productiehuis, persnieuws etc.

Ook de website van 'Box Office' (www.boxoffice.com) is een dankbare tool om horrorfilms te vinden. 'Box Office' geeft een overzicht van de opbrengsten van films. Dit impliceert dat we een overzicht krijgen van horrorfilms die al dan niet een breed publiek hebben bereikt. Hoewel 'You Tube' (www.youtube.com) niet geschikt is voor gerichte zoekacties kan het wel bijkomende informatie geven over horrorfilms, zoals de reacties van toeschouwers en links naar soortgelijke films. Daarenboven biedt het een platform waar gebruikers hun mening kunnen geven over bepaalde scènes en fragmenten. Naast de databanken hebben we lijsten teruggevonden in literatuur.

Er bestaan tal van horrorfilms en het is allerminst evident om een algeheel beeld te krijgen van de industrie. Vanzelfsprekend is het onmogelijk om tienduizenden films te onderwerpen aan een gedegen analyse. We hebben daarom enkele criteria opgesteld om onze zoektocht richting te geven. Een eerste criterium is de tijdscontext. Als we de nadruk willen leggen op culturele vernieuwing dan moeten we de evolutie van horrorfilms beter begrijpen net omdat innovatie afhankelijk is van context. We willen daarom films selecteren uit verschillende periodes van de filmgeschiedenis. Het volgende hoofdstuk zoomt hierop in.

Een tweede criterium is het bereik van horrorfilms, met name het aantal toeschouwers. We hebben er bewust voor gekozen om onze lens in te zoomen op 'mainstream' cinema (zeer groot bereik) en de zogenaamde 'cult films' (beperkt publiek). De reden waarom we ons hiertoe beperken heeft te maken met het feit dat bronnen over censuur hierdoor toegankelijk zijn. Daarenboven zijn het deze films waarover morele debatten zijn ontstaan, waaronder de sociale, politieke en filosofische toelaatbaarheid ervan. De kritische lezer zal de vraag poneren of we ons op deze manier niet te veel beperken tot commerciële westerse cinema. Ook niet-traditionele productiehuizen en industrieën hebben horrorfilms gemaakt die een groot of select publiek hebben bereikt. Onze selectie beperkt zich dus zeker niet tot westerse cinema.

Een derde criterium waar we rekening mee houden is het innovatieve karakter van horrorfilms. Zoals we zullen zien hebben verschillende horrorfilms een zekere (r)evolutie teweeggebracht. Dit zowel in de debatten over de morele toelaatbaarheid van bepaalde scènes die extreem gewelddadig zijn (censuur en niet censuur), het gebruik van 'special effects' en de introductie van nieuwe kunststrekkingen. 
Een vierde criterium heeft te maken met het onderscheid tussen horrorfilms en films waarin horror een rol speelt in het grotere verhaal. Vandaag gebruiken regisseurs choquerende scènes of beelden om bepaalde gebeurtenissen te accentueren of kracht bij te zetten. Een oorlogsfilm, bijvoorbeeld, kan evenzeer expliciete scènes bevatten die gevoelens van afkeer en gruwel opwekken bij het publiek. Onze focus ligt echter bij horrorfilms waarin de choquerende verhaallijn (extreem geweld) centraal staat. De reden hiervoor is dat we inzicht willen krijgen in het gebruik van sensatie en morele toelaatbaarheid van films waarin horror gebruikt wordt als hoofddoelstelling.

Een vijfde en laatste criterium betreft de morele toelaatbaarheid van horror. We hebben films geselecteerd die veel reacties en emoties hebben losgemaakt bij het publiek. In sommige gevallen hebben de films zelfs geleid tot censuur. Dergelijk criterium is belangrijk daar het ons toelaat een idee te krijgen van de sociaal-politieke context alsook de ethische vragen die gekoppeld zijn aan horror.

Aan de hand van deze criteria hebben we een vijftigtal films geselecteerd om onze doelstellingen te bestuderen ${ }^{3}$. We hebben onze data geanalyseerd door de films als het ware 'lezen' (Banks, 2001), dit wil zeggen dat we een korte beschrijving hebben gemaakt waarin we de nadruk hebben gelegd op inhoud en format (Banks, 2001). Dit wil zeggen dat een omschrijving hebben gegeven van technologie, sfeerschepping, verhaallijn, productie, regisseur, jaartal, setting en personages.

Vervolgens hebben we gefocust op context en sociale impact (Rose, 2007) van horrorfilms. Dit wil zeggen dat we hebben onderzocht of de horrorfilms en/of bepaalde scènes ervan onderworpen zijn geweest aan censuur of onderdeel hebben uitgemaakt van maatschappelijke debatten. Hiervoor hebben we beroep gedaan op literatuur en documentenanalyses. De volgende hoofdstukken geven een overzicht van onze bevindingen.

\section{3. 'Horror' extremer geworden? Een blik op de filmgeschiedenis}

In dit hoofdstuk schetsen we een beknopt historisch overzicht van horror in cinema (1896heden). Het resultaat is tot stand gekomen na een gedegen literatuurstudie en de empirische gegevensverzameling zoals hierboven omschreven. Om het overzicht te bewaren hebben we een tijdslijn gecreëerd waarin we films groeperen naargelang stijl. De tijdsafbakening hebben we getoetst aan twee vooraanstaande werken, met name 'A History of Horror' van W. Dixon (2010) en 'Film History' van K. Thompson en D. Bordwell (2003). Deze werken worden regelmatig gebruikt om periodes te schetsen in de filmgeschiedenis.

De doorwinterde filmliefhebber zal snel opmerken dat niet iedere strekking is opgenomen in het schema. Het is onze bedoeling om de voornaamste periodes weer te geven die min of meer bepalend zijn geweest voor het horrorgenre. Het is in geen geval onze bedoeling om een overzicht te geven van de geschiedenis van de film. Deze tijdslijn dient als illustratie om de lezer te introduceren in enkele belangrijke transities doorheen de filmgeschiedenis van het horrorgenre.

\footnotetext{
${ }^{3}$ Dit artikel bespreekt niet alle geselecteerde films omdat we de nadruk willen leggen op de bevindingen.
} 


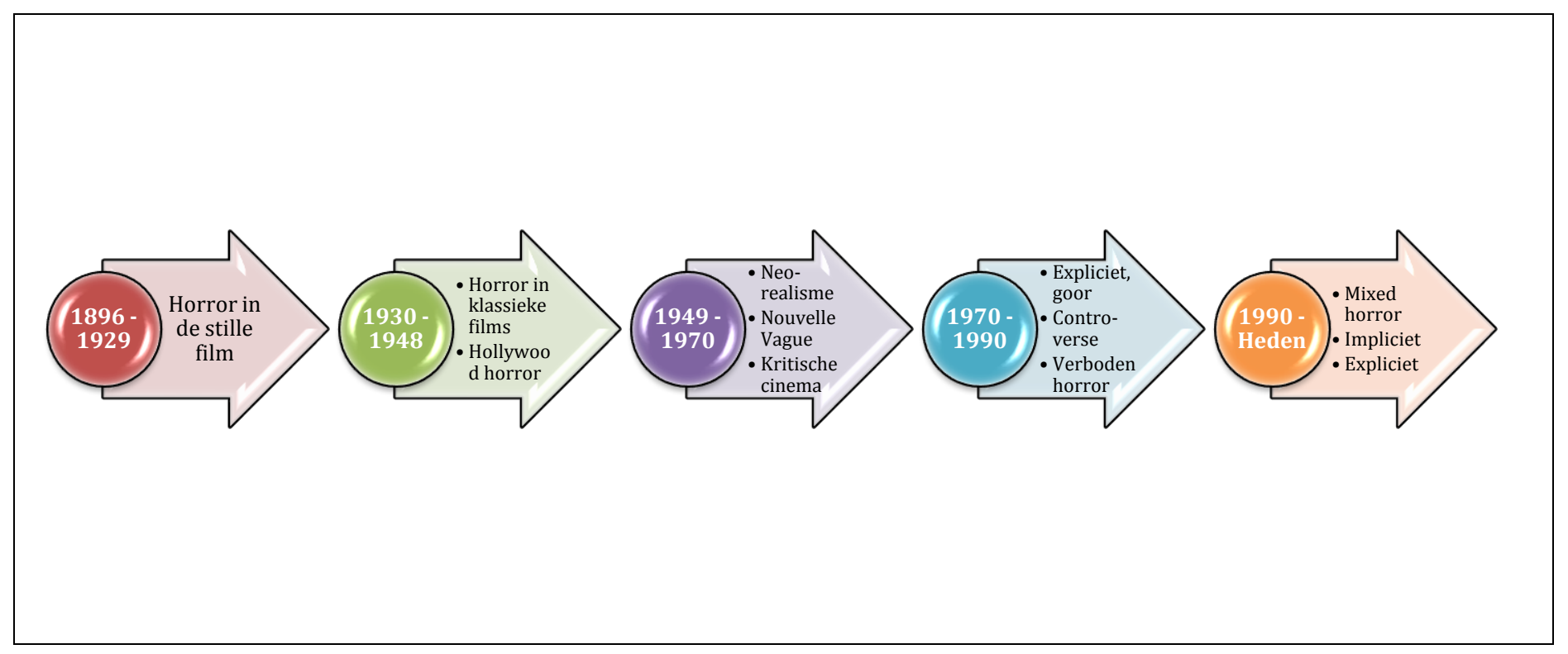

Afbeelding 1: Tijdslijn horrorfilms. Geraadpleegde werken: Dixon (2010) en Thompson \& Bordwell (2003).

\subsection{6-1929: Horror in de stille film}

Horror deed reeds zijn intrede tijdens de opkomst van de 'stille film', het beginpunt van de cinematografie. Film, als medium, werd aanzien als een ideaal middel om geweld in beeld te brengen. Méliès' 'Le Manoir du Diable' (1896) wordt doorgaan beschouwd als de eerste horrorfilm. In deze prent speelt de regisseur een vampier in een twee minuten durende kortfilm (Dixon, 2010: 4). De totstandkoming van een film in deze periode hing niet alleen af van de aanwezigheid van goede acteurs. Het decor was minstens zo belangrijk. Dit aspect zou in de verdere evolutie van de horrorfilms een belangrijk en centraal element worden. Mogen we ook niet vergeten dat het ontbreken van gesproken communicatie en geluid in films ertoe leidden dat sfeerschepping volledig afhankelijk was van locatie en visuele expressie.

Wie denkt dat in de periode van de stille film weinig expliciete scènes of beelden voorkwamen is verkeerd. Zo dateert de eerste authentieke "snuff film", dit is een film die een moord, een executie of een marteling in 'real time' laat zien, uit 1903. 'Electrocuting an Elephant' van Thomas Edison laat de executie zien van Topsy, een circusolifant op Coney Island. Het hele elektrocutieproces wordt gefilmd tot het moment Topsy dood neervalt (www.imdb.com).

In de periode van de stille film begon men reeds met de verfilming van 'Gothic Novelles' (Garrett, 2003). Hierbij spelen de gotische- middeleeuwse decors een belangrijke rol in de sfeerschepping. Ook de 'zwarte' kledij en de opvallende make-up zouden films zoals 'Dr. Jekyll and Mr. Hyde' (1908) van Otis Turner, 'Frankenstein' (1910) van J. Searle Dawley en de verschillende verfilmingen van 'The Picture of Dorian Gray' van Oscar Wilde op de filmhistorische kaart zetten. Niet alleen de gotische literatuur werd als bron van inspiratie gebruikt. Ook gedichten zoals Dante's Inferno waren gegeerde werken voor het uitschrijven van een horrorscenario.

De meest noemenswaardige periode is zonder twijfel deze van het Duits Expressionisme, Films zoals F.W. Murnau's 'Nosferatu' (1922) en Robert Wienes' 'Das Kabinett des Dr. Caligari' (1920) spreken vandaag nog steeds tot de verbeelding. Het Duits Expressionisme 
wordt in de filmgeschiedenis in het algemeen en in de horrorgeschiedenis in het bijzonder aanzien als een tijdperk waarin innovatie en vernieuwing centraal staan (Roberts, 2008). Dit omdat decors, het gebruik van licht, schaduwvorming en cadrages een centrale plaats kregen toebedeeld in horrorfilms. Gewelddadige scènes werden impliciet in beeld gebracht wat maakte dat de verhaallijn aan kracht moest winnen door de verbeelding van de toeschouwers (Bordwell \& Thomspon, 2001). Hetzelfde geldt voor het gebruik van het 'masker' als symbool van het kwade. Personages, zoals de vampier Nosferatu, worden onaantrekkelijk, grimmig en luguber, maar toch visueel sterk, in beeld gebracht. Een methode die filmmakers vandaag nog steeds toepassen.

Horror wordt in de periode van de stille film explicieter in beeld gebracht dan in het tijdperk dat zou volgen. Met de opkomst van filmstudio's en nieuwe technieken, zoals het gebruik van geluid, zou horror een minder uitgesproken betekenis hebben bij het publiek.

\subsection{0-1948: Horror en de opkomst van geluidfilms: Hollywood horror}

Met de opkomst van de geluidsfilm heeft het horrorgenre een nieuwe wending genomen. Acteurs moesten niet langer alleen de focus leggen op expressieve gelaatsuitdrukkingen. $\mathrm{Ze}$ moesten ook de gepaste stem hebben en communiceren met hun medeacteurs. 'Universal Pictures', de Amerikaanse filmstudio, domineerde tussen 1931 en 1948 in het maken van horrorfilms (Dixon, 2010: 25). Daarenboven werden 'filmsterren' gecreëerd door productiehuizen. Horror werd gecommercialiseerd waardoor men geweld veel meer impliciet zou weergeven. Daarenboven houdt Hollywood van statische decors en 'happy endings'. Horror stond in het teken van gematigdheid.

De invloeden van de 'Gothic Novels' bleven menig regisseurs inspireren en de gematigde geweldsscènes werden vertoond in alle rustiek en romantiek. Extreem geweld werd niet vertoond, mede door de invloed van de gigant 'Universal Pictures' aangezien zij geen voorstander waren van het vertonen van expliciete horrorscènes. Films uit die periode worden dan ook vaak bestempeld als 'de klassiekers'. Nochtans is deze strekking op het niveau van gruwel en extreem geweld minder uitgesproken aangezien het commerciële succes van filmstudio's dat niet toeliet.

Desondanks kwamen films, zoals 'Un Chien Andalou' en L'Âge d'Or' van Luis Bunuel en Salvador Dali, tot stand. Het gebruik van experimentele beelden en suggestie gaven een nieuwe wending aan film. Wat we niet zien, of denken te zien, zou meer centraal staan in de daaropvolgende periodes.

\subsection{9-1970: Horror tijdens de totstandkoming van nieuwe filmgenres}

Films tijdens deze periode hebben het pad voor de opkomst van extreem gewelddadige horrorfilms in de jaren ' 70 min of meer vrij gemaakt. Het feit dat er nood was aan een heropleving enerzijds en de introductie van televisie anderzijds hebben ertoe geleid dat horror veel explicieter in beeld werd gebracht (Dixon, 2010: 65). Televisie betekende de introductie van 3D beelden en gevarieerdere filmstijlen. Bepaalde filmscènes werden ook gedurfder zoals de introductie van naakt bij het brede publiek.

Tal van films hebben deze periode op de kaart gezet. Denken we onder meer aan de 'Night of the Living Dead' van Romero. Deze prent is een cultfilm geworden en zou talloze keren verfilmd worden. Het idee om zombies explicieter in beeld te brengen heeft ertoe geleid 
dat men ook ging experimenteren met make - up. Horror betekende een manier van experimenteren met nieuwe technieken.

Veel verder ging de film 'Blood Feast' uit 1963 van Herschell Gordon Lewis. Deze film is minder bekend bij het grote publiek maar is één van de eerste "gore" en expliciete "slasher films' in de geschiedenis van horror. Lewis werd aanzien als 'the wizard of gore' (Dixon, 2010: 124) en horrorfilms waren niet langer bedoeld voor mainstream cinema.

Deze periode staat ook bekend voor de opkomst van populaire horrorfilms en thrillers zoals 'Rosemary's Baby' van Roman Polanski uit 1968 en Alfred Hitchcocks' succesfilms waaronder 'Psycho'. Dergelijke films hebben ertoe geleid dat regisseurs op een meer impliciete manier voor sfeerschepping zorgden. Er werd geëxperimenteerd met montagetechnieken wat spanningsopbouw ten goede kwam.

\subsection{0-1990: Horror en het expliciete: de opkomst van het "gore"}

De jaren zeventig worden gekenmerkt door de introductie van gore en zeer expliciete horrorfilms bij het grote publiek. Daarenboven werden diverse kunststijlen geïntroduceerd. Het belang van beeldende kunst en het succes van soundtracks markeren deze periode. Horror en spanning wonnen aan kracht dankzij filmmuziek. Denken we hierbij aan, bijvoorbeeld, 'Jaws' (1975) van Steven Spielberg en gemaakt naar het gelijknamige boek van Peter Benchley. De suspense en de expliciete scènes waarin mensen aan stukken worden gereten door een grote witte haai hebben veel mensen de stuipen op het lijf gejaagd. De film heeft ertoe geleid dat tal van 'sequels' en gelijksoortige films het daglicht zagen.

Daarenboven zijn er in deze periode tal van horroriconen ontstaan zoals Jason Voorhees (Friday the 13th), Freddy Kruger (A Nightmare on Elm Street), Carrie (van Brian de Palma uit 1976, gebaseerd op het gelijknamige boek van Stephen King), Michael Myers (Halloween van John Carpenter ui 1978) en Leatherface (The Texas Chainsaw Massacre). Het succes van deze films vertaalde zich in de opkomst van sequels die in de $21^{\mathrm{e}}$ eeuw aanleiding gaven tot remakes. Horror werd gegeerd door selecte groepen van fans (cult) en suspense was geliefd door het publiek.

Ook de filmreeks 'Alien' van Ridley Scott drukte zijn stempel in de geschiedenis van horror. Het monster in de prent staat nog steeds bekend als één van de meest succesvolle creaties aller tijden. De kunstenaar H.R. Giger (Giger, 2007) gebruikt de samensmelting tussen industriële kunst en gotiek om de steeds grotere afhankelijkheid van onze samenleving van technologie te weerspiegelen. Er werd volop geëxperimenteerd met make up en styling waardoor filmmakers geweld explicieter in beeld konden brengen. Films zoals 'The Fly' van David Cronenberg uit 1986 en 'An American Werewolf in Londen' van John Landis hebben ertoe geleid dat transformaties van mensen in gemuteerde wezen op het witte doek zijn verschenen. De mogelijkheden waren nog niet geheel geavanceerd. Toch hebben ze ertoe geleid dat extreem geweld op het witte doek bekendheid verwierf bij een groot publiek.

\subsection{0-Heden: Horror en een mix van stijlen}

Hedendaagse horrorfilms laten zich definiëren door een mix van kunststijlen. Horror in dit tijdperk is zowel suggestief als expliciet. Daarenboven zijn de 'special effects' zodanig geëvolueerd dat gewelddadige scènes levensecht overkomen. Dit leidde tot verschillende remakes van, onder meer, 'A Nightmare on Elm Street' (2010). 
Dit tijdperk wordt eveneens gekenmerkt door de steeds voortdurende zoektocht naar sensatie. Met de opkomst van video en DVD's worden films meer verspreid wat de productie doet stijgen. De voortdurende druk om blijvend te innoveren betekent het gebruik van explicietere scènes. Denken we hierbij aan één van de meest controversiële films van de $21^{\mathrm{e}}$ eeuw, met name 'A Serbian Film' (2011). De film zit verweven van expliciete scènes van pedofilie en necrofilie. Hij staat in veel regio's ter discussie en is in verschillende landen verboden.

Deze periode wordt eveneens gekenmerkt door de introductie van horror bij kinderen en jongeren. Films zoals 'Battle Royale' van Fukasaku (2000) en 'The Hunger Games' van Garry Ross (2012) mikken hoofdzakelijk op een jong publiek. Hoewel de scènes minder expliciet in beeld gebracht worden is het inhoudelijk concept van beide films extreem gewelddadig. Jongeren moeten elkaar doden om te overleven in een dictatoriale samenleving.

\section{Slotbeschouwing: wordt horror steeds extremer?}

Filmmakers in het horrorgenre verleggen voortdurend hun grenzen en trachten innovatie gelijk te stellen aan meer sensatie en extremere vormen van geweld op het scherm. Als we kijken naar de periode 1970-1990 en 1990-heden zien we dat de focus op 'extreem geweld' hier visueel sterk tot uiting komt. Moorden en martelingen worden zeer gedetailleerd vertoond en de elementen 'goor', 'bloed' en 'pijn' krijgen een centrale plaats in de verhaallijn.

Hoewel expliciete horrorfilms de dag van vandaag min of meer vanzelfsprekend zijn is dit heus niet altijd het geval geweest. Verschillende periodes uit de filmgeschiedenis tonen aan dat extreem geweld op het scherm niet door het grote publiek aanvaard werd omdat ze morele discussies hebben opgewekt. Het gevolg hiervan is dat ze verboden en gecensureerd zijn geweest.

Horrorfilms hebben tot doel het publiek te choqueren. Aangezien de technologische vooruitgang van de laatste decennia ertoe geleid heeft dat 'special effects' waarheidsgetrouw overkomen bij toeschouwers is datgene wat we percipiëren als 'gruwelijk' veel 'extremer' geworden. Dit maakt dat horror vandaag een hoger sensatiegehalte heeft en door grote delen van het publiek als extreem beleefd wordt. Horrorfilms zijn hierdoor explicieter.

Tijdens de bespreking van de geschiedenis van de horrorfilm hebben we gezien dat het vertonen van expliciete beelden van extreem geweld hoofdzakelijk in de jaren zeventig gegeerd werd. Deze evolutie zou zich verder ontwikkelen in de jaren die volgen. Het resultaat hiervan is dat sommige films verboden zijn geweest of dat bepaalde scènes uit horrorfilms werden verwijderd. Deze evolutie is vandaag enigszins anders. De 'westerse cinema' kan in principe 'alles' van extreem geweld vertonen. Niettegenstaande deze evolutie impliceert dat er veel vrijer wordt omgegaan met moraliteit zijn hedendaagse mainstream horrorfilms minder expliciet dan vroeger. Horror binnen cultfilms is daarentegen een andere kwestie.

We kunnen onszelf de vraag stellen in hoeverre cineasten en producenten nog choquerende horrorfilms kunnen maken gelet op het feit dat kijkers steeds meer gewend geraken aan extreem geweld in westerse cinema. Het is niet meer evident voor een regisseur om een horrorfilm te maken waar het publiek van onder de indruk is. 
Dit artikel is opgebouwd rond de vraag of horror al dan niet extremer is geworden. De hamvraag blijft natuurlijk of het publiek minder gechoqueerd geraakt door horror en of we op een andere manier omgaan met sensatie.

\section{Bibliografie}

Boeken en artikels

Banks, M. (2011). Visual Methods in Social Research. London: Sage Publications.

Barker, C. (1986), The Hellbound Heart. London: Fontana.

Bordwell, D. \& Thompson, K. (2001), Film art: an introduction (sixth edition). Boston: McGraw-Hill.

Bradley, D. (2004), Behind the mask of the horror actor. London: Titan Books Ltd.

Baarda, D.B., De Goede, M.P.M., Teunissen, J. (2005). Basisboek Kwalitatief Onderzoek: Handleiding voor het Opzetten en Uitvoeren van Kwalitatief Onderzoek. Groningen: WoltersNoordhoff.

Decorte, T. \& Zaitch, D. (2010). Kwalitatieve Methoden en Technieken in de Criminologie. Leuven: Acco.

Dethier, H. (1996), Geschiedenis en problematiek van de film. Brussel: VUBPRESS.

Dixon, W.W. (2010), A history of horror. New Brunswick: Rutger University Press.

Egan, K. (2012). Trash or Treasure: Censorship and the Changing Meanings of the Video Nasties (Inside Poluar Film). Manchester: Manchester University Press.

Fukasaku, K. (2000). Battle Royale. Japan. AM Associates, Battle Royale Production Committee, Fukasaku - Gumi.

Garrett, P.K. (2003), Gothic reflections: narrative force in nineteenth-century fiction. Ithaca: Cornell University Press.

Giger, H.R. (2007). www HR Giger com. Keulen: Taschen.

Grimm, J. \& W. (1974). Kinder- und Hausmärchen gesammelt durch die Brüder Grimm (Illustrationen von Otto Ubbelohde und Vorwort von Ingeborg Weber-Kellermann). Frankfurt am Main: Insel Verlag.

Hayward, K. \& Presdee, M. (2010). Framing Crime: Cultural Criminology and the Image. New York: Routledge.

Landis, J. (2011). Monsters in the movies. Londen: Dorling Kindersley.

Lyng, S. (2004). Edgework: The Sociology if Risk-Taking. New York: Routledge. 
Markesinis, B. (2007). Good and Evil in Art and Law: An Extended Essay. Wenen: Springer.

Normanton, P. (2012). The Mammoth Book of Slasher Movies. Londen: Constable \& Robinson Ltd.

Pashley, V. \& Cools, M. (2013). Breaking Boundaries: Collapsing the Dark Side of Researching Criminology. In: Beyens, K, Christiaens e.a. (eds.), The Pains of Doing Criminological Research. Reeks: Criminologische Studies. Brussel: VUBPress.

Palmer, A. Fear: A Psychophysiological Study of Horror Film Viewing. Texas State University - San Marcos.

Poe, E.A. (2012), Edgar Allan Poe: complete stories and poems. New York: Barnes \& Noble Inc.

Roberts, I. (2008). German Expressionist Cinema: the World of Light and Shadow. Short Cuts. Wallflower. Columbia University Press.

Rose, G. (2007). Visual Methodologie: An Introduction to the Interpretation of Visual Material. London: Sage Publications.

Ross, G. (2012). The Hunger Games. USA. Lionsgate.

Shelley, M. (2003), Frankenstein (introduction and notes from Maurice Hindle). London: Penguin.

Stevenson, R.L. (1999), Dr. Jekyll and Mr. Hyde (introduction and notes from Dr. Tim Middleton). London: Wordsworth Classics.

Stoker, B. (2000), Dracula (introduction and notes from David Rogers). London: Wordsworth Classics.

Swanborn, P.G. (2008). Case - Study's: Wat, Wanneer en Hoe? Boom Onderwijs.

Thompson, K. \& Bordwell, D. (2003), Film history: an introduction (second edition). Boston: McGraw-Hill.

Van Dale (1996). Handwoordenboek Hedendaags Nederlands. Utrecht/Antwerpen: van Dale Lexicografie.

Vanderveen, G. (2010). Visuele Data en Methoden in de Criminologie. In: Decorte, T. \& Zaitch, D. (red.). Kwalitatieve Methoden en Technieken in de Criminologie. Leuven: Acco.

Wilde, O. (2003), The Picture of Dorian Grey (introduction and notes from Robert Mighall). London: Penguin.

Wetgeving 
Samenwerkingsakkoord van 3 oktober 2001 tot wijziging van het samenwerkingsakkoord van 27 december 1990 tussen de Vlaamse Gemeenschap, de Franse Gemeenschap, de Duitstalige Gemeenschap en de Gemeenschappelijke Gemeenschapscommissie van Brussel-Hoofdstad betreffende de oprichting, samenstelling en werking van de Intergemeenschapscommissie voor de Filmkeuring. B.S. 07 december 2012.

Koninklijk besluit van 27 april 2007 houdende oprichting van de Commissie voor de filmkeuring. B.S. 07 juli 2007.

\section{Websites}

www.boxoffice.com, meermaals en op verschillende tijdstippen geconsulteerd www.clivebarker.info, geconsulteerd op 02/08/2014, 9h31

www.imdb.com, meermaals en op verschillende tijdstippen geconsulteerd

Lijst geraadpleegde horrorfilms (op naam van de regisseur)

Alvarez, F. (2013). Evil Dead. USA. TriStart Pictures, FilmDistrict, Ghost House Pictures.

Barker, C. (1987). Hellraiser. UK. Cinemarque Entertainment BV, Film Futures, Rivdel Films.

Bunuel, L. \& Dali, S. (1929). Un Chien Andalou. Frankrijk. Vicomte de Noailles.

Bunuel, L. \& Dali, S. (1930). L'Âge d'Or. Frankrijk. Vicomte de Noailles.

Browning, T. (1931). Dracula. USA. Universal Pictures.

Buttgereit, J. (1988). Nekromantik. West Duitsland.

Castoldi, G.L., Fenton, H., Grainer, J., Mendik, X. \& Petley, J. (2011). Cannibal Holocaust \& the Savage Cinema of Ruggero Deodato. Surrey: FAB Pres Ltd.

Carpenter, John (1978). Halloween. USA. Compass International Pictures, Falcon International Productions.

Chen, K. (1993). Farewell My Concubine. China. Beijing Film Studio, China Film CoProduction, Maverick Picture Company.

Christopherson, P. \& Reznor, T. - Nine Inch Nails (1993). The Broken Movie. USA.

Christensen, B. (1922). Häxan. Zweden. Aljosha Production Company, Svensk Filmindustri (SF).

Clark, A. (1895). The Execution of Mary, Queen of Scots. USA. Edison Manufacturing Company.

Craven, W. (1984). A Nightmare on Elm Street. USA. New Line Cinema, Media Home Entertainment, Smart Egg Pictures. 
Craven, W. (1996). Scream. USA. Dimension Films/Woods Entertainment.

Cronenberg, D. (1986). The Fly. USA/UK/Canada. SLM Production Group, Brooksfilms.

Cunningham, S.S. (1980), Friday the 13th. USA. Paramount Pictures, Georgetown Productions Inc., Sean S. Cunningham Films.

Dawley, J.S. (1910). Frankenstein. USA. Edison Manufacturing Company.

Deodato, R. (1980). Cannibal Holocaust. F.D. Italië. Cinematografica.

De Palma, B. (1976). Carrie. USA. United Artists.

Edison, T. (1903). Electrocuting an Elephant. USA. Edison Manufacturing Company.

Friedkin, W. (1973). The Exorcist. USA. Warner Bros./Hoya Productions.

Gillespie, J. (1997). I Know What You Did Last Summer. Columbia Pictures Corporations, Mandalay Entertainment, Summer Knowledge LLC.

Hitchcock, A. (1960). Psycho. USA. Shamley Productions.

Hooper, T. (1974). The Texas Chain Saw Massacre. USA. Vortex.

Kerekes, D. \& Slater, D. (1993). Killing for Culture: An Illustrated History of Death Film from Mondo to Snuff. Londen: Creation Books.

Kubrick, S. (1980). The Shining. USA. Warner Bros., Hawk Films, Peregrine).

Landis, J. (1981). An American Werewolf in Londen. UK/USA. PolyGram Filmed Entertainment/Lycanthrope Films.

Lewis, H.G. (1963). Blood Feast. USA. Friedman-Lewis Productions.

Méliès, G. (1896). Le Manoir du Diable. Frankrijk. Georges Méliès. Star Film.

Méliès, G. (1902). Voyage dans la Lune. Frankrijk. Star Film.

Murnau, F.W. (1922). Nosferatu, eine Symphonie des Grauens. Duistland. Jofa-Atelier Berlin-Johannisthal, Prana-Film GmbH

Myrick, D. \& Sanchez, E. (1999). The Blair Witch Project. USA. Haxan Films.

Palmer, M.A. (2008). Fear: A Psychophysiological Study of Horror Film Viewing. Texas State University.

Pasolini, P.P. (1975). 120 Days of Sodom. Italië/Frankrijk. Produzioni Europee Associati (PEA), Les Productions Associés. United Artists. 
Peli, O. (2007). Paranormal Activity. USA. Solana Films/Blumhouse Productions.

Polanski, R. (1968). Rosemary's Baby. USA. William Castle Productions.

Raimi, S. (1981). The Evil Dead. USA. Renaissance Pictures.

Romero, G.A. (1969). Night of the Living Dead. USA. Image Ten, Laurel Group, Market Square Productions.

Romero, G.A. (1974). Dawn of the dead. USA/Italië. Laurel Group.

Roth, E. (2005). Hostel. USA. Hostel LLC, International Production Company, Next Entertainment.

Schumacher, J. (1999). 8mm. USA/Duitsland. Columbia Pictures Corporation, Hofflund/Polone, Global Entertainment GmbH \& Company Medien KG.

Scott, R. (1979). Alien. USA. Brandywine Productions, Twentieth Century-Fox Productions.)

Six, T. (2011). The Human Centipede II. USA. Six Entertainment Company.

Slade, D. (2007). 30 Days of Night. USA/New Zealand. Ghost House Pictures/Columbia Pictures

Spasojevic, S. (2010). A Serbian Film. Servië. Contra Film.

Spielberg, S. (1975). Jaws. USA. Universal Studios.

Turner, O. (1908). Dr. Jekyll and Mr. Hyde. USA. Selig Polyscope Company.

Vogel, F. (2001). August underground. USA. Toe Tag Pictures.

Wan, J. (2003-2010). Saw Franchise. USA. Evolution Entertainment, Saw Productions Inc. en Twisted Pictures.

Wiene, R. (1920). Das Cabinet des Dr. Caligari. Duistland. Decla-Bioscop.

Wiseman, L. (2003). Underworld. UK/Hongarije/Duitsland/USA. Lakeshore Entertainment, Laurinfilm, Subterranean Productions LLC. 